\section{Encouraging reflection: good doctor or bad doctor?}

Sarah Brand, (iD Patrick Lancaster, Irene Gafson \& Helen Nolan

What problems were addressed? Medical students have been shown to have variable perceptions of reflection, ${ }^{1}$ despite its integration into medical schools' curricula and the General Medical Council's encouragement of the concept throughout medical careers. This project focused on producing a tool for self-reflection that is creative, engaging and easy to use. This took the form of a booklet containing the reflections of others and an area for self-reflection by graduating students.

What was tried? Patients, doctors and other health professionals were interviewed and asked only two questions: What are the qualities of a 'good' doctor? What are the qualities of a 'not so good' doctor? Various themes emerged amongst the different groups and a representative sample of quotations was collated. The booklet, entitled Good Doc, Bad Doc, was created with the aim of producing an aesthetically pleasing end product. The front section of the booklet was dedicated to quotations derived from responses to question 1 (What are the qualities of a 'good' doctor?), and the back section contained quotations derived from responses to the questions on the qualities of a 'bad' doctor. The centre of the booklet contained an area for selfreflection and the reader was encouraged to consider what he or she thought made a 'good' or 'bad' doctor at different stages of a career.

The aim of the project was to present the booklet to the graduating medical students of 2016 so that they could use it as a tool for self-reflection throughout their careers. The booklet was initially presented to a focus group of final-year medical students. Their response was overwhelmingly positive. It provided an excellent source of discussion among the group, who were eager to see themes in the responses given and used it to reflect on their own practice. The group felt that in reality this tool would be best used at the earliest possible stage of medical school and could be used to track the learner's maturing views on professional behaviour. They felt that then, once the booklet had proven to be a useful resource, they would be more likely to take it into their work following graduation.

What lessons were learned? In light of the input given by the focus group, the booklet was used as originally intended and presented to graduating doctors in 2016. The original focus group will be followed up and the impact of the booklet fully assessed at this time.

The development of the original project to introduce the booklet at the beginning of medical school, alongside a discussion on the use of reflective practice, can be planned. The practicability and effectiveness of using this as a tool for self-reflection at an earlier stage will be further evaluated and compared with the original project and its follow-up results.

REFERENCE

1 Sargeant J, Eva KW, Armson H, Chesluk B, Dornan T, Holmboe E, Lockyer JM, Loney E, Mann KV, van der Vleuten CPM. Features of assessment learners use to make informed self-assessments of clinical performance. Med Educ 2011;45 (6):636-47.

Correspondence: Sarah Brand, Postgraduate Education Centre, Lister Hospital, Coreys Mill Lane, Stevenage SG1 4AB, UK. Tel: 441438 314333; E-mail: sarahbrand@nhs.net doi: $10.1111 /$ medu. 13449 